
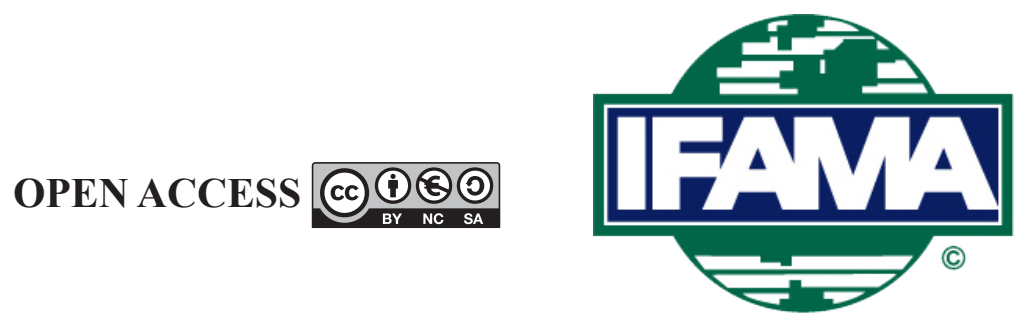

International Food and Agribusiness Management Review

Volume 23, Issue 1, 2020; DOI: 10.22434/IFAMR2018.0116

Received: 14 November 2018 / Accepted: 16 September 2019

\title{
Can China's food production capability meet her peak food demand in the future?
}

Based on food demand and production capability prediction till the year 2050

\section{RESEARCH ARTICLE}

\author{
Du Yuneng ${ }^{\mathrm{a}}$, Xu Youliang ${ }^{\mathrm{b}}$, Zhang Leiyong ${ }^{\mathrm{c}, \mathrm{d}}$ and Song Shufang ${ }^{(\mathrm{i} e}$ \\ ${ }^{a}$ Associate professor, ${ }^{b}$ Postgraduate student, ${ }^{e}$ Lecturer, College of Economics \& Management, \\ Anhui Agricultural University, No.130 Changjiangxi Road, Hefei, Anhui 230036, P.R. China \\ 'Senior manager, Postdoctoral Research Center of Hefei Xingtai Financial Holdings \\ (Group) Co., Ltd., No.1688 Qimen Road, Hefei, Anhui 230071, P.R. China \\ ${ }^{d}$ Post doctor, School of management, University of Science and Technology \\ of China, No.96, JinZhai Road, Hefei, Anhui 230026, P.R. China
}

\begin{abstract}
With the increase of food demand in China and the growth of world population, whether China can meet her peak food demand in the future or not has become an issue worth study. By consolidating relevant factors of food demand in China, the peak food demand is predicted to occur in 2036, and the peak food demand amount is predicted at 758.17 million tons by factor and synthetical analysis. Through factor consolidation and scenario test, the following policy implications have been unearthed: China's food production capability is crucial to maintain her future food security; improving the gain yield is the key method; monitoring China's population change and formulating appropriate population policies are important; reducing food waste, curbing unreasonable consumption and promoting healthy and green diet are needed; construction of high standard farmland will be significant in maintaining the food security; and excessive stored food should be de-stocked in a timely manner.
\end{abstract}

Keywords: food supply, food demand, food production capability, China JEL code: Q18, Q01

\footnotetext{
${ }^{\circledR}$ Corresponding author: ssfahau@qq.com
} 


\section{Introduction}

China's food security has been a global concern both in policy research and academic research for many years (Cui et al., 1952). In 1995, Brown published the paper 'Who Will Feed China' (Brown, 1995), which awakened Chinese policymakers to the shocking reality about China's food security. From today's perspective, Brown's prediction seems to be a false alarm because China has basically realized food self-sufficiency for decades, and the gross food production has kept growing from 2004-2015, for twelve consecutive years (Peng et al., 2017). However, in recent years food imports to China have been soaring quickly. In 2017, China imported more than 130.6 million tons of food, including 95.5 million tons of soybean, 2.8 million tons of corn, 4.4 million tons of wheat, 4.0 million tons of rice, 8.9 million tons of barley, and 5.1 million tons of sorghum. Total food imports increased by $13.9 \%$ in 2017. Meanwhile, gross food production in China was 617.9 million tons, including 2.8 million tons of food export, so the net food import was 127.8 million tons, and China's food self-sufficiency rate stood at only $82.9 \%$ for the year 2017 . This figure prompted some researches to argue that the food security situation in China was getting worse (Ghose, 2014; He et al., 2017). On the other hand, the world food security situation could turn out to be even worse (Perez et al., 2017). All these make China's future sustainable food supply a topic worthy of study.

The grim prospect led to a question: can China's food production capability meet her peak food demand and maintain sustainable food supply in the future?

From current data, China is becoming the world's biggest food importer despite her substantial food stock, so the current food situation in China could be called a situation of 'Three Highs': high production, high stock, and high import. An interpretation for this illogical phenomenon is mainly that the food price in China's domestic market is higher than the international market, because the price support policy dictates that the government should purchase the farmers' crops at a certain price higher than that of the international market. This phenomenon shows that China might not be weak in food production capability but is plagued by high cost of domestic food production (Wang et al., 2018). In the future, if the food price in the world market continues to be lower than the Chinese domestic market, China can keep on importing food; but if the food supply in the world market cannot meet the demand and the food prices go higher than the Chinese domestic market, then food production capability will become the crucial factor to ensure China's food security. For example, in 201784.5 million tons of foods we restocked in the National Grain Storehouses ${ }^{1}$. This number cannot be ignored if one wants to really understand China's true food security situation. However, to our knowledge, the stocked food and food production capability in China received much less attention than net food import. Very few studies explicitly explored food production capability in China's food security context (Fang and Cheng, 2009).

Food security is affected by many factors, such as changes in the structure of food consumption, agricultural production conditions, natural conditions, population size and age structure, agricultural support and protection policies, and changes in the international food market. In different stages of economic development, these factors play different roles. So, any research on food security should take important related factors into consideration. Although the factors affecting food security are wide-ranging, they can be summarized into two aspects: demand and supply. In recent years, in terms of demand, with the improvement of the living standards of the Chinese people, new changes have taken place in grain consumption, such as the change in the total population, the age structure of the population, the upgrading of the level of food consumption, and the increase of industrial grain consumption. In terms of food supply, the Chinese government has vigorously pushed forward the reform of agricultural supply and proposed the idea of 'storing grain in land and technology' (Shen et al., 2018), which implies improving land productivity and agricultural technology. In this study, we focus on predicting China's peak food demand by taking all these factors into consideration. In particular, we adopted a comprehensive literature research that is suitable for the analysis of different but related factors to predict the future food demand and production capability from the perspective of sustainable development.

$\overline{{ }^{1} \text { http://www.gov.cn/xinwen/2018-01/22/content_5259150.htm (in Chinese) }}$ 
Table 1. Consolidation of factors of China's food security.

\begin{tabular}{lll}
\hline & Positive/negative aspects & Factors \\
\hline Demand & $\begin{array}{l}\text { positive } \\
\text { negative }\end{array}$ & $\begin{array}{l}\text { aging rate } \\
\text { urbanization rate } \\
\text { dietary change } \\
\text { industrial use of grain } \\
\text { population size }\end{array}$ \\
& positive & $\begin{array}{l}\text { construction of high standard farmland } \\
\text { negative }\end{array}$ \\
& $\begin{array}{l}\text { yield growth using agricultural technology } \\
\text { adoption of grain producing policies } \\
\text { decrease of arable land }\end{array}$ \\
& climate change \\
\hline
\end{tabular}

The rest of the study is structured as follows. First, the factors that are related to future food demand and production capability are defined according to comprehensive literature research. Second, the food demand baseline is defined according to related research reports and literatures. Third, future food demand till the year 2050 is predicted by taking each factor respectively and a certain method was used to synthesize all those factors. Fourth, future food production capability is predicted, and scenarios for domestic production of food to supplant different food imports are tested. Finally, policy implications are given in this study.

\section{Definition of relevant influencing factors}

As a hot topic, China's food security issue has been widely discussed, especially the prediction aspect. Since food security is influenced by multiple factors, the first step of this study is to determine these factors.

In terms of food demand, obviously that population is the decisive factor, which includes urbanization rate, population growth rate and aging rate. Urbanization will reduce arable land, increase grain needed per capita, and also cause soil pollution. These results are all pernicious to China's food security (Chen, 2007). After the one child policy gave way to the universal two-child policy, a likely change of the population growth rate will influence China's population peak both in number and time, which in turn may bring new problems to China's food security (Yan, 2018). Aging rate affects China's food security through arable land concentration, decrease of per capita grain consumption, and also the opportunity for big scale operation of arable land (Minetal, 2017). The second significant factor to affect China's food demand is the changing structure of food consumption which includes the rising consumption of meat among young people, and the growth of industrial uses for grain (Xie and Marchant, 2015). Theoretically speaking, feed grain and industrial grain will significantly raise the level of grain consumption, which will also increase the food demand.

In terms of food supply, some scholars argue that the farmland is the most basic factor, because in the current technical conditions, farmland area and quality are still the main factors affecting food production capability (Burkle et al., 2017; Lipton and Saghai, 2017). Specifically, the farmland factor can be divided in to two sub-factors, which are construction of high standard farmland and decrease of arable land (Nath et al., 2015). The former is positive (Zhang et al., 2014), while the latter turns out to be negative (Deng et al., 2015). Apart from farmland, there are other important factors like the climate change, agricultural technical progress and food producing policy. Climate change would increase crop yield in some parts of China (Ye et al., 2013), but other researches showed that the net output of Chinese agriculture would decrease because of climate change (Tao et al., 2011; Wu et al., 2014; Zhao et al., 2014). In this study, we perceive climate change as a negative factor to food security, so that a cautious prediction can be made. Agricultural technology can improve the productivity of crops significantly and has become an important breakthrough in the future to ensure food security in China (Song et al., 2016). Food producing policies adopted by the Chinese government 
concern food security, agricultural environmental protection, land use, agricultural support protection, and so on (Rada et al., 2015; Yi et al., 2015). These policies are positive factors.

Since there are so many factors related to China's food security, an explicit method should be figured out and those factors taken into consideration. To test whether China can feed herself mainly with domestic crop production or not, the fundamental measuring method is comparing future food consumption with future food production capability. Even if crop import is now relatively high, it doesn't mean China's food security situation is severe, because at least for now the world food market can provide enough food for China at a price lower than Chinese domestic food market (Clapp, 2017). To our knowledge, research on future food consumption and food production capability including these related factors is not enough (Wu et al., 2016), and food stock in China hasn't been appropriately considered in Chinese food security studies. Therefore, in this study, ten factors related to China's food security were classified into two groups: one concerns future food demand, while the other is related to future food supply. Each group falls into two sub-categories, positive and negative. Table 1 presents these factors in a three-level manner.

China plans to realize her basic and full modernization by 2035 and 2050 respectively. In addition, Chinese population may reach the peak around the year 2030 according to the Chinese government report ${ }^{2}$, so we chose the time range 2017-2050, which can cover the most severe moments of China's food security in the future, to test if China can maintain her food security to fulfill the modernization plan and determine whether China's food security situation will find relief or not.

\section{Materials and methods}

According to relevant researches (Chodur et al., 2018; Fujimori et al., 2014; Godrich et al., 2017; Liu et al., 2018a), each factor will be discussed in detail to predict its value in future, especially the peak value and the final value in 2050. Only in this way can the peak food demand and production capability in China be predicted. The values of the ten specific factors will be predicted through these following methods: (1) find the current value of each factor as the start point; (2) find the peak value and its appearing time for each factor from government plans, relevant regulations, and relevant researches; (3) find the final value for each factor according to trend analysis. After that, their impacts on food consumption or production capacity will be evaluated quantitatively.

\subsection{Baseline definition}

The data baseline is from the year of 2017, because data release is always lagging behind. According to domestic grain production in China, the net grain import, crop stocks, and the population ${ }^{3}$, we summed up the domestic production and the net grain import, then subtracted the grain stocks, and obtained per capita demand for food was $475.7 \mathrm{~kg}$, which comprised of ration grain $(47.1 \%)$, feed grain $(28.5 \%)$, and industrial use of grain ${ }^{4}(24.4 \%)$. Therefore, the baseline for grain consumption in China in 2017 was about $475.7 \mathrm{~kg}$ per capita (224.0 kg ration grain, $135.6 \mathrm{~kg}$ feed grain and about $116.1 \mathrm{~kg}$ industrial grain). Figure 1 shows the proportion of China's food demand structure.

\footnotetext{
${ }^{2}$ http://www.xinhuanet.com/finance/2017-01/26/c_1120383716.htm (in Chinese)

${ }^{3}$ Data from 'The Statistical Bulletin of the People's Republic of China on National Economic and Social Development in 2017' http://www.stats. gov.cn/tjsj/zxfb/201802/t20180228_1585631.html (in Chinese)

${ }^{4}$ Estimate from 'Development status and market prospect of China's grain industry in 2016' http://www.chyxx.com/industry/201604/408743.html (in Chinese)
} 


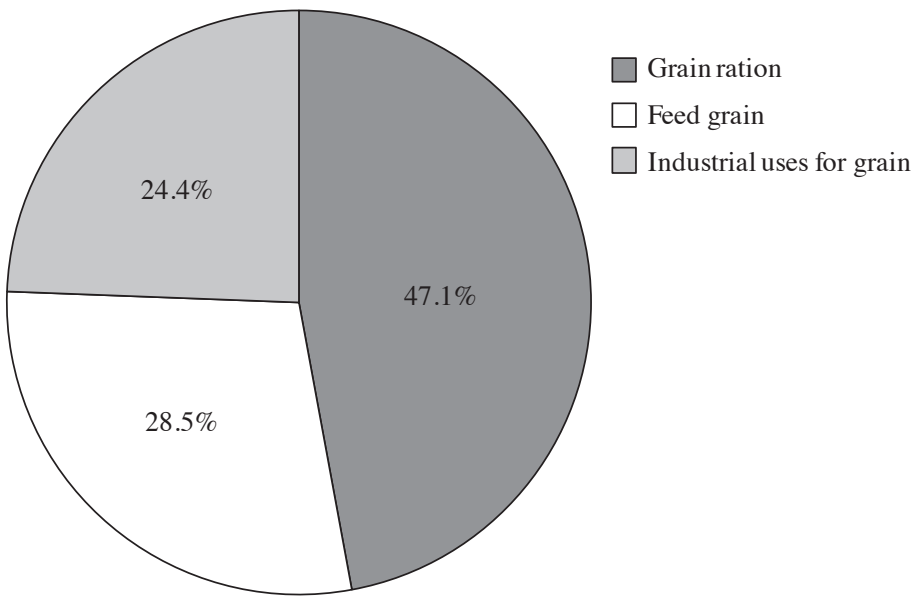

Figure 1. Proportion of China's food demand structure.

\subsection{Future food demand prediction}

Aging rate is a positive factor to food security, since the elderly consume less food than the youth. In 2017 the number of people over 60 years old was more than 240.9 million, accounting for $17.3 \%$ of China's population. This rate will peak at over $34.9 \%$ in the year $2050^{5,6}$ According to relevant research (Bai et al., 2014), when the aging rate rises $1 \%$, meat consumption will drop $0.5 \%$ in China. If we merely take this change into consideration, meat consumption will fall by about $8.8 \%$, which means feed grain will also fall by $8.8 \%$ in 2050 . Figure 2 shows the trend of food demand change per capita, taking only the aging rate change into consideration.

As a symbol of modernization, urbanization rate will rise smoothly since urbanization is China's national strategy (Cao et al., 2014). The urbanization rate in 2017 was $58.5 \%$, still lower than developed countries like the USA and European countries. Many researches (Gao and Wei, 2013; Gu et al., 2017) argued that the urbanization rate in China would be above $70 \%$ in 2035. In order to give an accurate prediction for food

\footnotetext{
${ }^{5} \mathrm{http}: / /$ www.askci.com/news/finance/20180123/155928116673.shtml (in Chinese)

${ }^{6}$ Data from 'Report on the development of China's pension fund' https://news.qq.com/a/20161210/014297.htm (in Chinese)
}

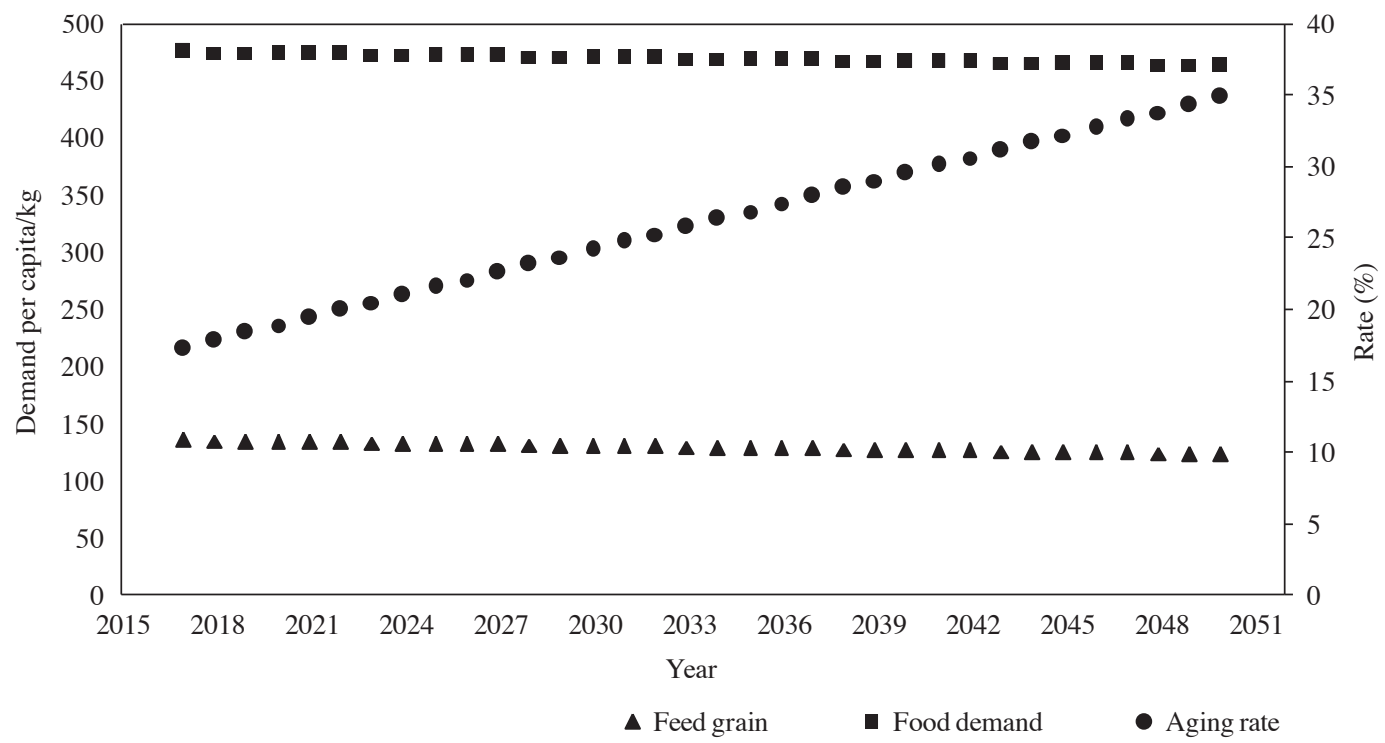

Figure 2. Food demand change per capita taking only the aging rate change into consideration. 
consumption, urbanization rate in China is set at $90 \%$ in 2050 to make sure we do not underestimate its negative impact on food security in China. According to relevant research (Xin et al., 2015), food consumption of urban people was about $18 \%$ higher than rural people in 2015, but this urban-rural gap in China would taper off in the near future and disappear after 2050. Accordingly, food consumption of urban people will be the same with rural people in 2050. It means that the food consumption difference between urban people and rural folks, which was about $18 \%$ in favor of the urbanites in 2015 , was probably reduced to $16.97 \%$ in 2017 and will vanish in 2050.

In Equation 1, $X$ refers to the per capita grain need for rural people in $2017, R_{\mathrm{i}}$ refers to the urbanization rate in $i$ year, and $\gamma_{\mathrm{i}}$ refers to the proportion difference between urban and rural people's food consumption per capita in $i$ year.

$$
R_{\mathrm{i}} \times(\gamma i+1) \times X+\left(100 \%-R_{\mathrm{i}}\right) \times X=359.6
$$

In Equation 1, $X$ was calculated as $327.1 \mathrm{~kg}$. With the data and equation, the future grain demand per capita could also be figured out by merely taking urbanization rate into consideration. Future food consumption change as a result of urbanization can be acquired. Figure 3 shows the future urbanization rate trend until the year 2050 by linear interpolation, and also the increase of food consumption per capita by considering urbanization only.

Over the last decades, Chinese people have dramatically increased their consumption of meat, other livestock products, and fruits, which resulted in a decrease of the consumption of grain-based foods. According to relevant researches (Liu, 2016; Xin et al., 2015), the food consumption per capita would increase to 386.5 $\mathrm{kg}$ in 2030 because of the dietary change, and stay stable after that, because healthy dietary habits would become popular in the future. Therefore, we believe food consumption per capita will be around $400 \mathrm{~kg}$ in 2050. Figure 4 shows the future food demand trend caused by Chinese dietary change. Through polynomial regression, the food demand is predicted to be $386.5 \mathrm{~kg}$ and $400 \mathrm{~kg}$ in 2030 and 2050 respectively.

China's industrial use of grain has kept growing for decades, with more and more grains being used to produce biofuel, alcoholic products and other industrial products. Some researches claimed that China's industrial use of grain would see a spectacular growth in the future (Peng, 2017; Xiao et al., 2017b). According to the

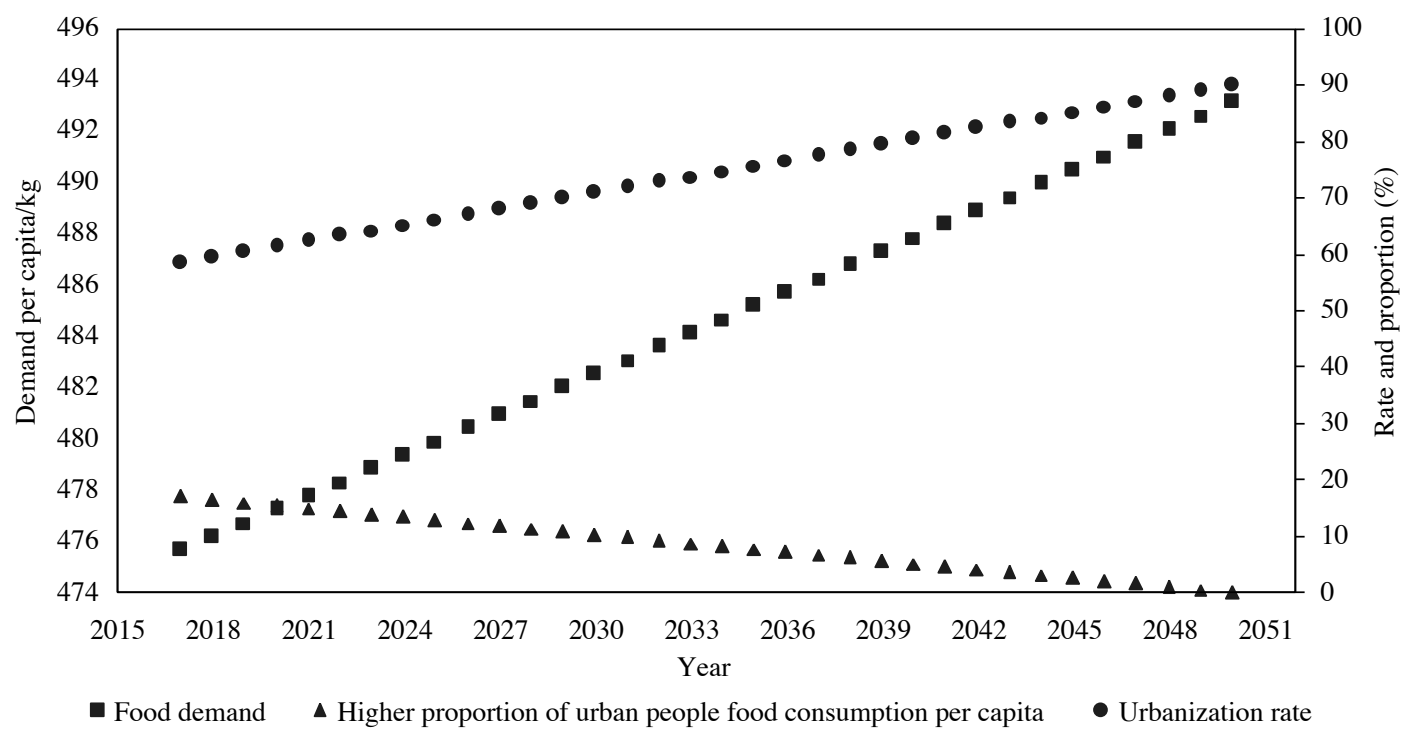

Figure 3. Change of food demand per capita by taking only urbanization rate change into consideration. 


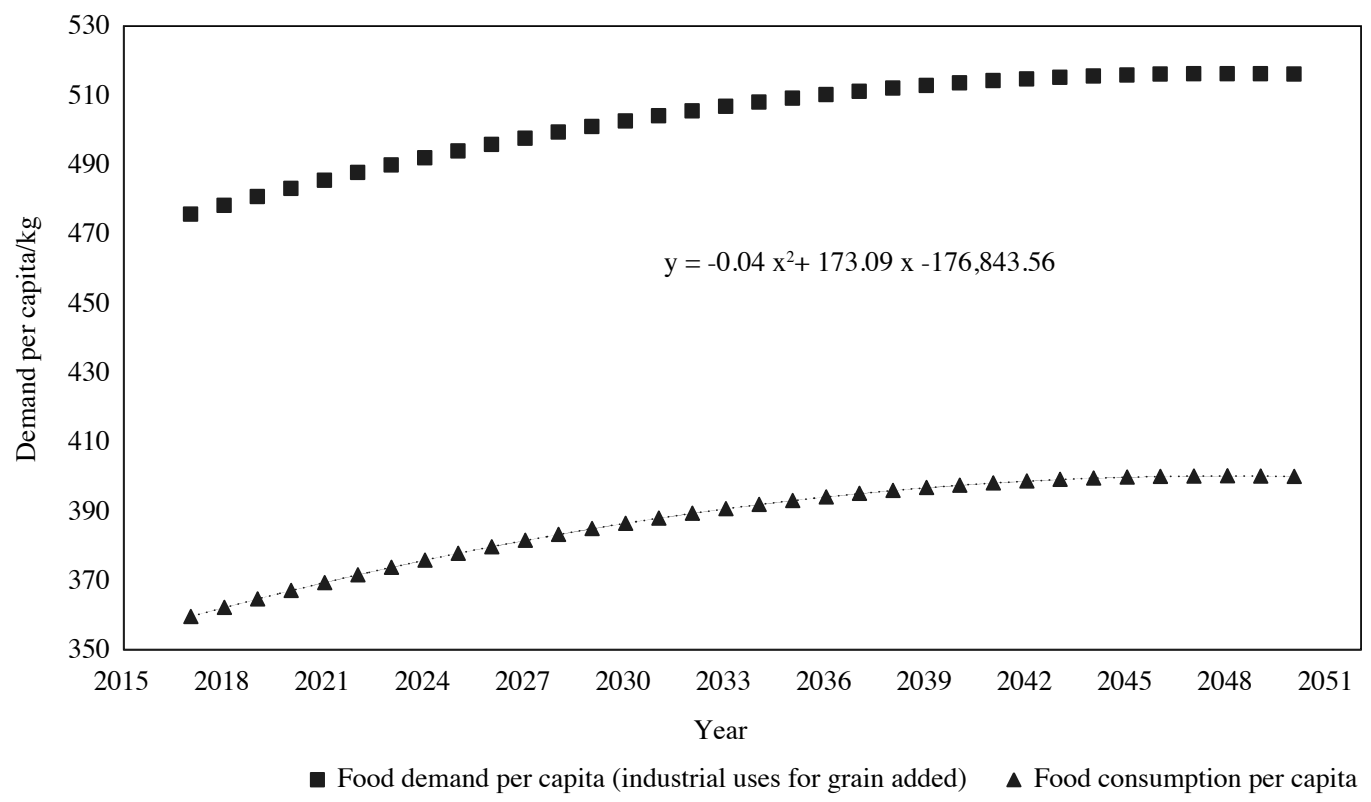

Figure 4. Change of food demand per capita by taking only the dietary changes into consideration.

data collected from National Bureau of Statistics ${ }^{7}$, and relevant researches, the annual growth rate of China's industrial per capita use of grain will be around $0.9 \%$ currently and $0 \%$ in 2050 , because industrialization would be fully achieved by 2050. Figure 5 shows China's future industrial use of grain by linear interpolation from the year of 2017 to 2050 .

Population size is a crucial factor to total food demand. The growth rate of China's population was $0.43 \%$ in 2017, which was the lowest in recent years. As it appears that the growth rate wasn't affected so much as expected by the introduction of the universal two-child policy, a few recent researches argue that the peak of China's population may be lower and may come earlier than previous predictions (Chen and Xiufeng,

$\overline{{ }^{7} \text { http://www.stats.gov.cn/tjzs/tjsj/tjcb/dysj/201503/t20150313_693961.html (in Chinese) }}$

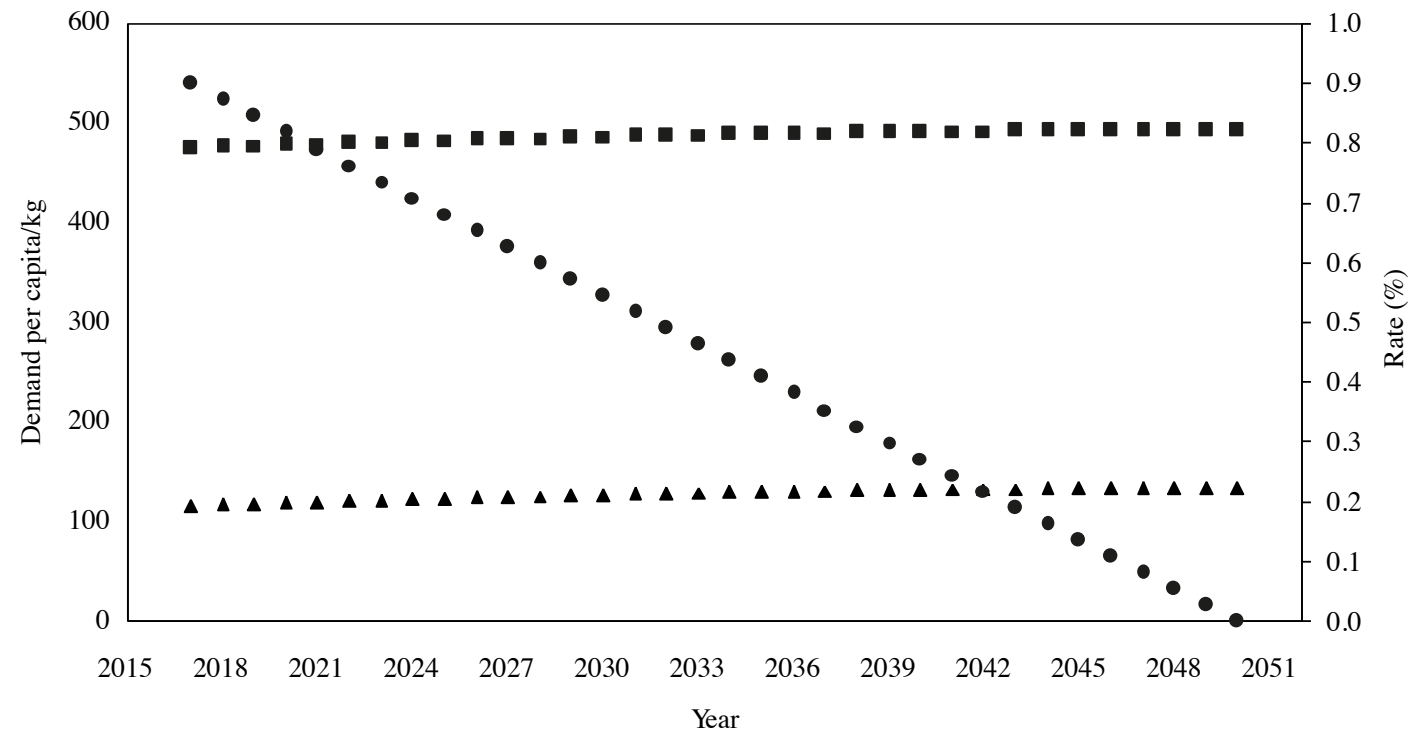

\ China's industrial used grain per capita — Food demand per capita - Growth rate of China's industrial used grain

Figure 5. Change of food demand per capita by considering only industrial use of grain. 
2014; Liu et al., 2017) peak probably in $2020 \mathrm{~s}^{8}$. In spite of some researches arguing that China's population may reach the peak even in 2021, in order to give a conservative estimate, we used the data adopted by National Health and Family Planning Commission of China, which shows China's population would reach the peak at about 1.45 billion in 2030. After 2030, China's population will decrease to around 1.3 billion in 2050 according to relevant researches (Feng et al., 2018; Xiao et al., 2017b) and a national population development plan for 2016-2030 ${ }^{9}$. Table 2 shows China's future population trend predicted by quadratic regression from the year 2017 to 2050 .

\subsection{Synthetical prediction of food demand}

After considering all the above factors, a proper way to synthesize them should be formulated. Referring to the relevant research (Valin et al., 2014), we multiplied the food demand per capita of each year with the corresponding population.

In Equation 2, $X_{\mathrm{j}}$ refers to the food demand per capita prediction in $j$ year, and $\Delta X_{\mathrm{ij}}$ refers to the increased or decreased part as compared to the food demand per capita in 2017 caused by $i$ factor in $j$ year.

$$
X_{\mathrm{j}}=\left(X_{2017}+\Delta X_{1 \mathrm{j}}\right)+\left(X_{2017}+\Delta X_{2 \mathrm{j}}\right)+\ldots+\left(X_{2017}+\Delta X_{\mathrm{ij}}\right)-(i-1) \times X_{2017}
$$

The total food demand $D_{\mathrm{j}}$ in $j$ year is calculated by Equation 3:

$$
D_{j}=X_{j} \times P_{j}
$$

where $P_{\mathrm{j}}$ refers to China's population in $j$ year.

Figure 6 shows the trend of food demand per capita, the total food demand and population according to formulas 1-3 and Tables 1 and 2.

\footnotetext{
$\overline{{ }^{8} \mathrm{http}: / / \text { business.sohu.com/20160203/n436819866.shtml (in Chinese) }}$

${ }^{9} \mathrm{http}: / /$ www.hindustantimes.com/world-news/china-s-population-will-peak-at-1-45-billion-around-2030-says-government/storyRO1snkgzMEUkmK8VR9HssO.html
}

Table 2. China population trend by quadratic regression.

\begin{tabular}{llll}
\hline Year & China population (billion) & Year & China population (billion) \\
\hline 2017 & 1.390 & 2034 & 1.443 \\
2018 & 1.399 & 2035 & 1.440 \\
2019 & 1.407 & 2036 & 1.436 \\
2020 & 1.415 & 2037 & 1.431 \\
2021 & 1.422 & 2038 & 1.425 \\
2022 & 1.428 & 2039 & 1.419 \\
2023 & 1.433 & 2040 & 1.412 \\
2024 & 1.438 & 2041 & 1.404 \\
2025 & 1.442 & 2042 & 1.395 \\
2026 & 1.445 & 2043 & 1.386 \\
2027 & 1.447 & 2044 & 1.376 \\
2028 & 1.449 & 2045 & 1.365 \\
2029 & 1.450 & 2046 & 1.353 \\
2030 & 1.450 & 2047 & 1.341 \\
2031 & 1.449 & 2048 & 1.328 \\
2032 & 1.448 & 2049 & 1.314 \\
2033 & 1.446 & 2050 & 1.300 \\
\hline
\end{tabular}




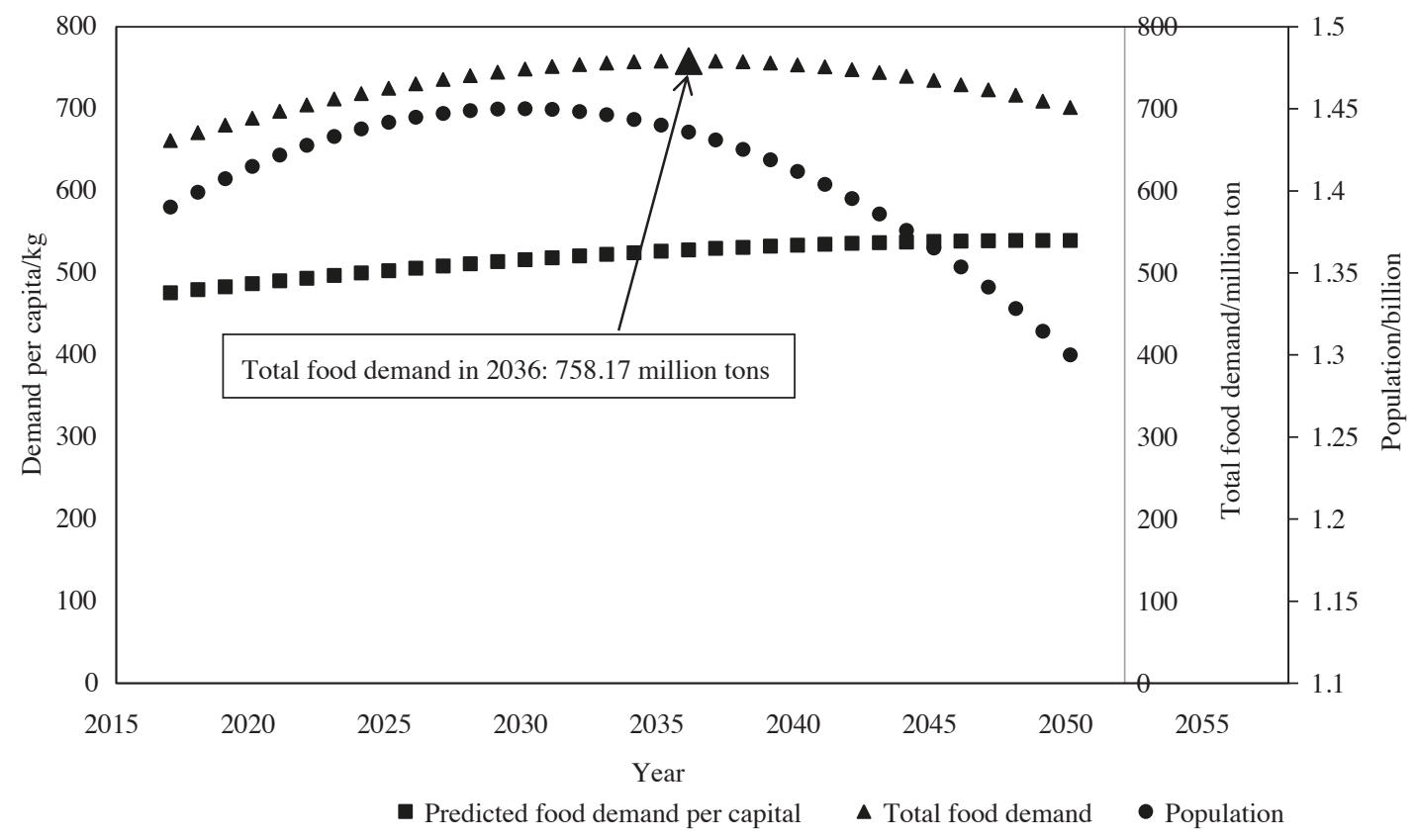

Figure 6. Future total and per capita food demand trend with population change.

According to Figure 6, in 2036, the total food demand in China will reach a peak of 758.17 million tons. This result not only involves different factors related to the food demand, but is also highly consistent with other studies and research reports ${ }^{10}$ (Anderson and Strutt, 2014; Fukase and Martin, 2016; Gregory, 2013).

\subsection{Sensitivity analysis of the food demand prediction}

Because food demand is influenced by several factors, it is necessary to find which factor is more sensitive to food demand. In the following section, a sensitivity analysis is explained.

From Table 3, it can be seen that China's peak food demand serves as target value, while aging rate, urbanization rate, population, dietary change, industrial use of grain are sensitivity factors. The table shows the result of the sensitivity analysis, which was made in a one-factor-at-a-time manner at the rate of $-10,-5$, 5 and $10 \%$ to see how much change would happen in relation to peak food demand.

Table 3 shows that population is the most sensitive factor to China's peak food demand, and dietary change and industrial use of grain are also significant factors, while urbanization rate and aging rate are less sensitive.

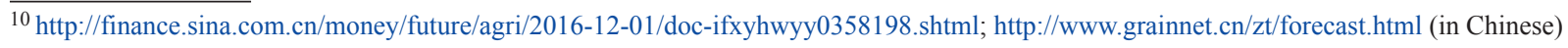

Table 3. Factor sensitivity analyses of peak food demand.

\begin{tabular}{llllll}
\hline \multicolumn{6}{l}{ Peak food demand changing rate caused by sensitivity analysis respectively } \\
\hline $\begin{array}{l}\text { Changing rate } \\
(\%)\end{array}$ & $\begin{array}{l}\text { Aging rate } \\
(\%)\end{array}$ & $\begin{array}{l}\text { Urbanization } \\
\text { rate (\%) }\end{array}$ & $\begin{array}{l}\text { Population } \\
(\%)\end{array}$ & $\begin{array}{l}\text { Dietary change } \\
(\%)\end{array}$ & $\begin{array}{l}\text { Industrial use } \\
\text { for grain (\%) }\end{array}$ \\
\hline-10 & 0.13 & -0.18 & -10 & -7.46 & -2.48 \\
-5 & 0.06 & -0.09 & -5 & -3.73 & -1.24 \\
5 & -0.07 & 0.09 & 5 & 3.73 & 1.24 \\
10 & -0.13 & 0.17 & 10 & 7.46 & 2.47 \\
\hline
\end{tabular}


So even if the growth rate of China's population is quite low currently, population monitoring should still be carried out especially after the introduction of the universal two children policy. Besides, a healthy and low-calorie diet structure should be promoted to the public. Regarding the industrial use of grain, as it is needed in China's industrialization progress, looking for new energy sources is an important way to control its growth.

In the context of total food demand increasing in China, food production capability is the most important counterpart to meet this kind of increase, especially in the scenario of global population growth and tight food supply in the future. So, assessing Chinese food production capability and testing whether it can meet the increasing food demand or not is discussed in the following part. It should be noted that the year 2036 might not be the most serious year with regards to food security, because the situation of food production capability and world food trade market might be different then as compared to now.

\subsection{Future food production capability prediction}

In this section, similar logic and methods are used to address this issue. But different from the food demand prediction, a crop yield scenario test is carried out. The first basic parameter for food production is the availability of arable land. Because of industrialization and urbanization, the area of China's arable land has been decreasing for the past few decades. In 2016 arable land in China was pegged at 1,349,566 km² according to Ministry of Land and Resources. The outline of national land planning ${ }^{11}$ points out that in 2050 arable land will diminish to $1,200,000 \mathrm{~km}^{2}$. We believe that the area of arable land would not shrink to less than $1,200,000 \mathrm{~km}^{2}$ because arable land protection is a 'red line' policy in China. Another basic parameter for food production is the yield level of China's arable land. Currently, the average grain yield in China is $5,506 \mathrm{~kg} / \mathrm{ha}$, while the cereal yield in the United States was reported at 8,143 in $\mathrm{kg} / \mathrm{ha}$ in accordance with the World Bank collection of development factors (FAO, 2017). Hence, there is still plenty of room for grain production growth in China. In 2016, multiple cropping indicator in China was $121.9 \%$, and grain acreage was 1,130,282 $\mathrm{km}^{2}$ as reported by National Bureau of Statistics of China (In 2017, the grain acreage decreased to $\left.1,122,200 \mathrm{~km}^{2}\right)^{12}$. Using the above data as baseline, we selected the grain yield and grain-sown areas as main parameters, which in turn would be influenced by construction of high standard farmland, yield growth using agricultural technology, adoption of grain producing policies, decrease of arable land, and climate change.

Construction of high standard farmland is being widely carried out in China's rural areas. According to the Chinese government plan ${ }^{13,14}, 533,333 \mathrm{~km}^{2}$ high standard farmlands will be constructed by the year 2020 , and in 2030 the area of high standard farmland might reach $800,000 \mathrm{~km}^{2}$. As per the regulation ${ }^{15}$ of the Chinese government's and the growth speed of high standard farmland construction, by 2050 high standard farmland will reach $1,000,000 \mathrm{~km}^{2}$ at least. Generally speaking, the yield level will increase at $15-20 \%$ according to government media ${ }^{16}$. In order to conservatively estimate the increase in food production capability, we believe that the yield level of the high standard farmlands will increase by $15 \%$ and become less vulnerable to natural disasters like droughts and floods. Figure 7 shows arable land, high standard farmland, and the yield growth rate caused by high standard farmland construction calculated by Equation 4:

$$
Y_{\mathrm{i}}=\left(H_{\mathrm{i}} / A_{\mathrm{i}} \times 1.15+\left(A_{\mathrm{i}}-H_{\mathrm{i}}\right)\right) / A_{\mathrm{i}} / Y_{2016}-1
$$

$Y_{\mathrm{i}}$ refers to the yield level in $i$ year, $H_{\mathrm{i}}$ refers to the high standard farmland in $i$ year, $A_{\mathrm{i}}$ refers to the total arable land in $i$ year, and the $Y_{2016}$ refers to the yield level in 2016. Figure 7 shows the trend of yield growth rate from 2016-2050 by merely taking high standard farmland construction into consideration.

\footnotetext{
${ }_{11}$ http://finance.china.com.cn/roll/20160622/3776645.shtml (in Chinese)

12 http://www.stats.gov.cn/tjsj/ndsj/2017/indexch.htm (in Chinese)

${ }^{13} \mathrm{http} / / /$ www.gov.cn/zhengce/content/2015-08/07/content_10057.htm (in Chinese)

${ }^{14} \mathrm{http}: / /$ www.gov.cn/zhengce/content/2017-02/04/content_5165309.htm (in Chinese)

$15 \mathrm{http}: / / \mathrm{www} . x i n h u a n e t . c o m /$ fortune/2018-10/28/c_129980765.htm (in Chinese)

${ }^{16} \mathrm{http}: / / w w w . m o f . g o v . c n / z h e n g w u x i n x i / c a i z h e n g x i n w e n / 201507 / t 20150728 \_1385910 . h t m l$ (in Chinese)
} 


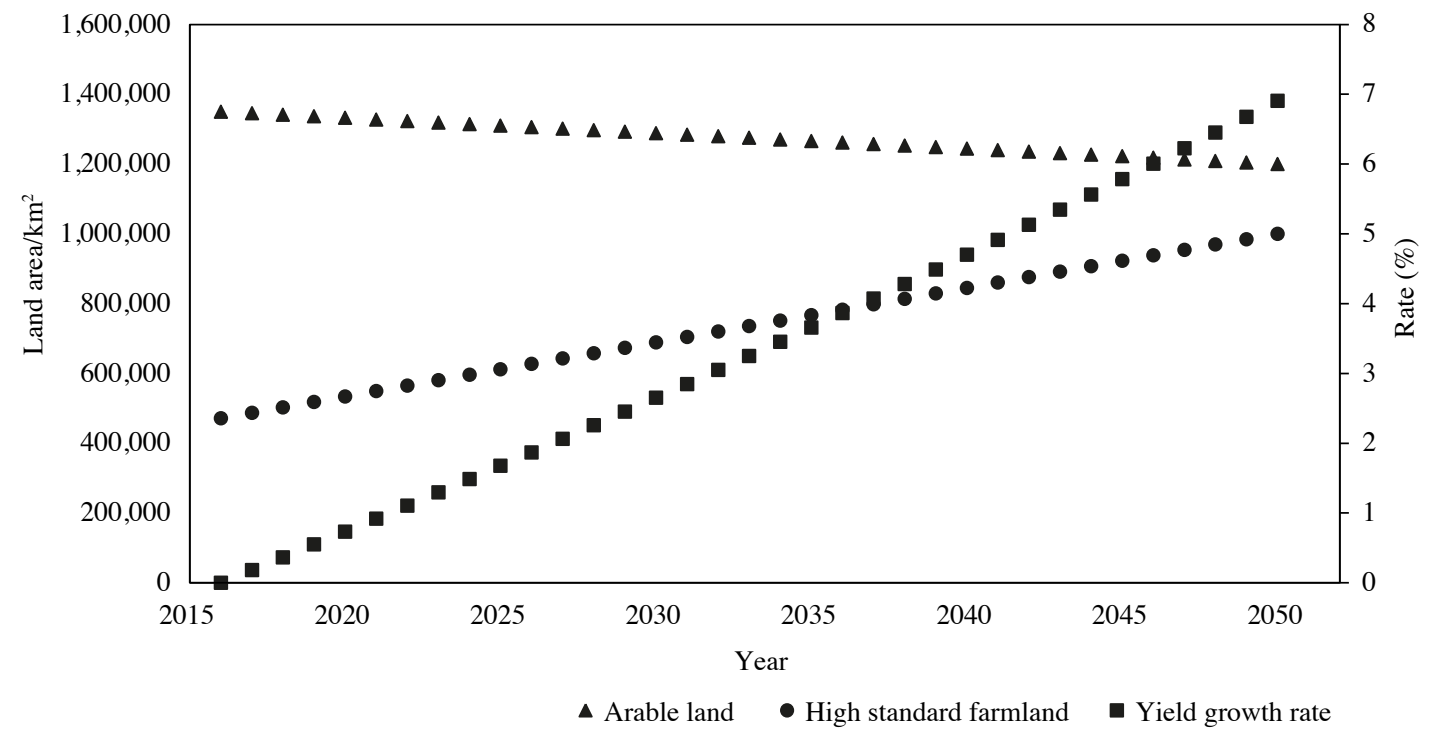

Figure 7. Trend of yield growth rate influenced by high standard farmland construction only.

It is held that China's food yield level has kept growing during the past decades, and agricultural technology advancement is the main factor responsible for yield increase (Dazhuan et al., 2017). In this study we leave the yield prediction at the end of the method part and use scenario testing to find what will be the amount of yield level that can meet the food demand peak in 2037.

Multiple cropping indicator is another potential factor of food production capability, and in recent decades the multiple cropping indicator has been rising (Liang et al., 2016), but we believe that room for multiple cropping indicator growth will be limited due to climate change and loss of rural labor. It is proposed that the maximum multiple cropping indicator would not exceed 1,400\% for grain production (Chen et al., 2016).

From 2004, the Chinese government implemented grain subsidy policies, after which grain production has increased for 12 years in a row. To ensure food security is a core problem that would require the development of agriculture and even national economy in China, so we believe that related policies will keep supporting grain production in China. This is a positive factor for food capacity, which can stimulate food production as needed. So, in this study grain producing policy is regarded as a 'Push' factor to ensure a sustained growth of grain yield, regulate the multiple cropping indicators, and retain the grain-sown areas.

Most of the studies on climate change and grain yield showed that extreme events could have the greatest impact on grain yield (Qiao et al., 2017; Tao et al., 2016; Xiao et al., 2017a). However, because of the construction of high standard farmland with better irrigation and water conservation, China's agriculture can better withstand natural disasters. We believe that climate change will not have serious impact on China's grain yield. According to relevant research (Ma et al., 2015), in 2050 the reduction of China's grain yield will not exceed $5 \%$, if we merely take climate change as a factor. Since high standard farmland will increase the average yield, while climate change can bring negative impact, we multiplied the two trends, and got the yield growth rate by taking these two factors together. Figure 8 shows the two factors almost offset each other.

Because food diversity is becoming more and more popular in China, the extension space of grain acreage is limited since a considerable part of arable land will be used to produce vegetables, fruits and other cash crops. With reference to some relevant researches (Liu et al., 2018b; Tao and Zhou, 2014) and the adoption of grain producing policies, we believe that the grain acreage will retain the current level $\left(1,120,000 \mathrm{~km}^{2}\right)$. 


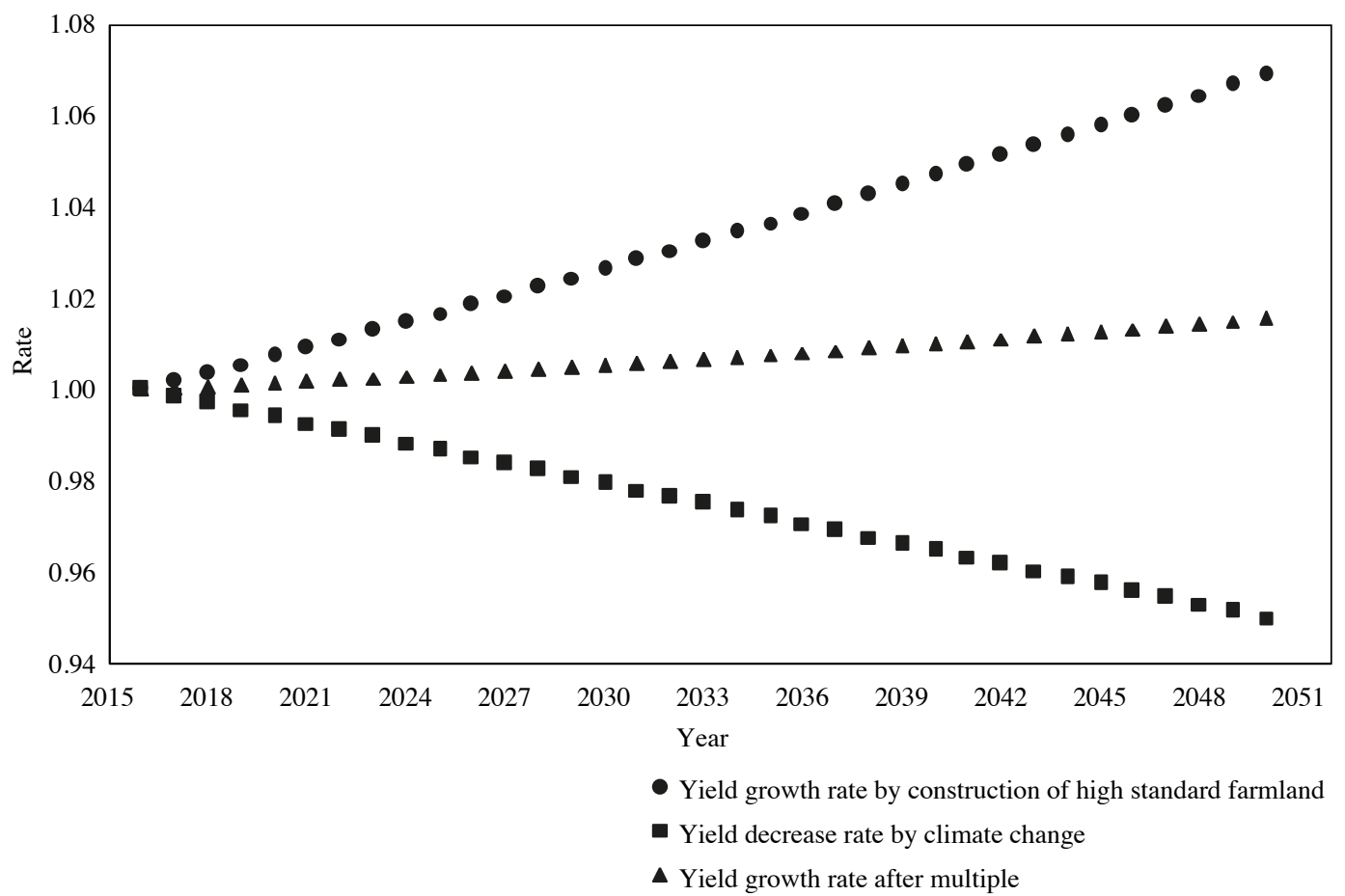

Figure 8. Trend of grain yield by taking climate change and high standard farmland construction into consideration.

\section{Results}

\subsection{Food production by China's domestic industry to replace different food import scenarios}

In addition to promoting the yield level, the supply capacity of the international food market can provide another way to maintain the food security of China. In 2017, global food trade was 408 million tons, more than $30 \%$ of which were imported by China (FAO, 2019). Since the world population is projected to reach 9.8 billion in 2050, food supply will become severe year by year, and the world food market might not meet the import demand of China (UN, 2017). In the following, a scenario test was carried out by setting food import at three different levels. The first level is 127.8 million tons, kept unchanged until the year 2050; the second is a gradual decrease to half that amount, i.e. 63.9 million tons in 2050; the third level is a sharper reduction to zero by 2050 . Table 4 summarizes the three food import scenarios.

As we have mentioned before, in 2017 the gross domestic food production in China was 617.9 million tons, while the net food import and the food stock were 127.8 and 84.5 million tons respectively. So, the actual amount of food China needed in 2017 was 661.2 million tons, which is calculated by adding the domestic food production to the net food import and minus the food stock. In the first scenario, we see that in 2036 China needs to produce 630.37 million tons of food, not much higher than the gross domestic food production

Table 4. Three food import scenarios.

\section{Scenario assumptions}

Amount of grain that can be imported in 2050

\begin{tabular}{lll}
\hline First scenario & The international market is well supplied with grain & 127.8 million tons \\
Second scenario & The grain supply decrease in the international market & 63.9 million tons \\
Third scenario & The international market cannot provide excess food & zero \\
\hline
\end{tabular}




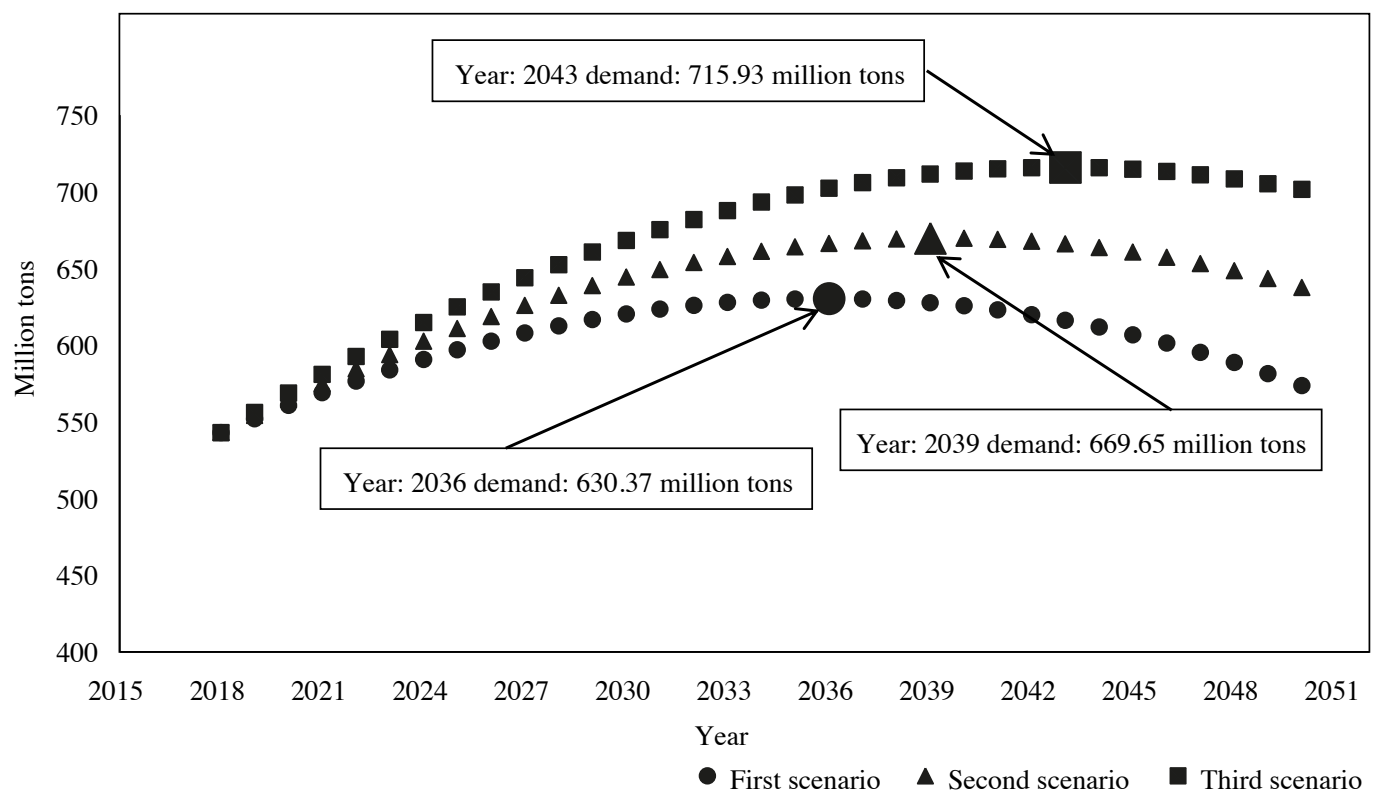

Figure 9. Senior manager trends of food domestically produced in different food import scenarios with the peak year highlighted.

in 2017. If the world food market could keep supplying food to China at the same level as in 2017, China's food security level should sail smoothly through the peak demand of 2036. However, because of the growth of world population, the world food market probably could not supply as much food to China as in 2017. In the second scenario, the peak demand on gross domestic food production will happen in 2039, reaching 669.65 million tons, which is significantly higher than the demand of 2017. In the third scenario, coupled with the shortage of international food supply, the peak demand on gross domestic food production will happen in 2043, to the tune of 715.93 tons, which is way higher than the demand of 2017. In order to tide over the third scenario, food yield should increase to $6,379 \mathrm{~kg} / \mathrm{ha}$ in 2043 from 5,506 kg/ha in 2017, which means that the food yield level in China should increase by $15.8 \%$. From Figure 9 we also notice that China's food security situation can well experience a relief after the most severe moment. Figure 9 shows the trends of food domestically produced in different food import scenarios, with the peak year highlighted.

\subsection{Limitations of the study}

Subjectivity is a problem that needs to be avoided but cannot be completely overcome in any prediction research. Most of the basic data and prediction data in this study are collected from official reports and official websites to avoid subjectivity and arbitrariness in data adoption. Even so, we are aware that there is an inevitable bias in any prediction study. In order to solve the problem of subjectivity in this prediction research, any change of relevant indicators will be tracked in future research, and the results of the research will be revised accordingly.

\section{Policy implications}

China's food production capability is crucial to future food security in China and even the world. As the world's population grows, the world's food supply will increasingly be in shortage in the future (Diouf, 2009), so food production capability is crucial to maintain not only China's food security but even global food security. In respect of grain production, the most sensitive factors are the grain-sown areas and the grain yield. Therefore, maintaining the red line of arable land and increasing the level of grain yield are the two key measures to meet the peak of China's future grain demands. 
There is no serious food security threat to China at present. That is why it is not accurate to evaluate China's food security situation from the perspective of imports only. In 2017, China imported more than 130.6 million tons of food, causing many researches to argue that China's food security situation was in serious trouble (Du et al., 2014; Gandhi and Zhou, 2014; Ghose, 2014; Huang and Yang, 2017; Jiang, 2015). But in fact, about 84.5 million tons of foods were purchased by the government to augment food stock, which was over 500 million tons in $2017^{17}$. This storage amount was almost as much as the total food demand of 2017 , so there have never been any serious food security problems in recent years. The main reason for the large amount of food imports was that international food prices were lower than China's domestic food prices. If international food prices remain low, importing food is a rational choice for China.

Improving the grain yield is the key method to meet the future food demand in China. This study shows that China's peak food demand will arrive around 2036, when the total food needed in China will increase to 758.17 million tons, $14.66 \%$ higher than the demand of 2017 . To complicate this situation further, grain acreage will not increase or might even decrease instead. The positive factor of high standard farmland will also be offset by the effects of climate change (e.g. water shortage). So, yield level and a hopefully robust global food market will be the key factors to sustain China's food security. China should come up with the technology to increase the yield level by $15.8 \%$ to meet the worst scenario. A big challenge as it appears, such increase is likely, because the cereal yield ( $\mathrm{kg} / \mathrm{ha}$ ) in United States was reported at $8,143 \mathrm{~kg} / \mathrm{ha}(\mathrm{FAO}$, 2017), which is way higher than China's yield level, so there is still plenty of room for food production growth in China. In order to meet the future food demand, measures should be taken to improve the technology of food production. What's more, with growth of China's purchasing power fueled by its GDP growth, China can import food more easily, as long as the international food prices remain reasonable.

Monitoring China's population change and devising the right population policy are important to the question of food security issue in China. In recent years the population birth rate in China has been declining, but, with the introduction of the universal two child policy and more liberal population policies, changes in the population of China are still uncertain. Since population is a key factor that determines food security, a real-time monitoring of variations in China's population is needed. At the same time, population control measures will still be necessary in the context of food security.

Reducing food waste, curbing unreasonable consumption and promoting healthy and green diet are also important ways to ensure China's food security. At present, the dietary structure of both urban and rural residents is changing. While the intake of cereal food and vegetables remains stable, consumption of animal food (meats) and dairy products is on the rise. China is still in the developing stage, so of the food consumption and waste generation continue to climb. Therefore, it is necessary to control the diet balance for China's food security.

Construction of high standard farmland and arable land preservation are quite important to maintain China's food security level. Compared with the USA, China's arable lands are low and medium yield in many places, so construction of high standard farmland should be continued in earnest by the Chinese government. In recent years, China's grain production has been relatively large, and this can lead to huge waste, as grains stored for a long time are consigned to animal feed or industry. Building high standard farmlands is a better choice, as it enables grain to be stored in arable land instead of grain warehouses.

Other ways to alleviate the food situation is to promptly de-stock excess store when the stored grain exceeds the national security target. Instead of allowing spoilage or over storage, the excess food can be used for food processing industries, biomass energy production, foreign aid on humanitarian grounds and alternative foods processing industry to replace imports, etc. Even fallow cultivation can be encouraged to reduce the food storage during relevant years. After the excess food storage is de-stocked, the saved custodial fees and

\footnotetext{
$\overline{{ }^{17} \mathrm{http} / / / \text { finance.sina.com.cn/money/future/agri/2017-05-19/doc-ifyfkkmc9740252.shtml (in Chinese) }}$
} 
price subsidies can be used to invest in fallow subsidy for cropland rotation. This will not only help protect limited farmland resources, but also increase farmers' income.

\section{Acknowledgements}

This research is supported by National Social Science Foundation of China (No.15CJY052, No.14CJY041), Key Project of Humanities and Social Sciences Research in Anhui Universities (No. SK2018A0129), and Hefei Scientific Research Project for Postdoctoral Research Center (Project hosted by Zhang Leiyong). Many thanks to Lokho Hepuni Kayina (hkayina@ustc.edu.cn) and Dr. Sun Bo for the language editing.

\section{References}

Anderson, K. and A. Strutt. 2014. Food security policy options for China: lessons from other countries. Food Policy 49: 50-58.

Bai, J.F., S. Min, H.G. Qiu and X.B. Wang. 2014. Impact of population aging on China's meat consumption. China Soft Science 11: 17-26.

Brown, L.R. 1995. Who will feed China? Wake-up call for a small planet. London England Earthscan Publications, London, UK.

Burkle, L.A., C.M. Delphia and K.M. O’Neill. 2017. A dual role for farmlands: food security and pollinator conservation. Journal of Ecology 105(4): 890-899.

Cao, S., Y. Lv, H. Zheng and X. Wang. 2014. Challenges facing China's unbalanced urbanization strategy. Land Use Policy 39(39): 412-415.

Chen, J. 2007. Rapid urbanization in China: a real challenge to soil protection and food security. Catena 69(1): $1-15$.

Chen, S. and L.I. Xiufeng. 2014. Research on the grain producers around the year of Chinese population peak. Asian Agricultural Research 6(12): 14-17.

Chen, Y.J., Y.I. Xiaoyan, L.N. Fang and R.Z. Yang. 2016. Analysis of cultivated land and grain production potential in China. Scientia Agricultura Sinica 49(6): 1117-1131.

Chodur, G.M., X. Zhao, E. Biehl, J. Mitrani-Reiser and R. Neff. 2018. Assessing food system vulnerabilities: a fault tree modeling approach. BMC public health 18(1): 817-827.

Clapp, J. 2017. Food self-sufficiency: making sense of it, and when it makes sense. Food Policy 66: 88-96.

Cui, Z., Z. Dou, X. Chen, X. Ju and F. Zhang. 1952. Managing agricultural nutrients for food security in China: past, present, and future. Agronomy Journal 106(1): 191.

Dazhuan, G.E., H. Long, Y. Zhang and T.U. Shuangshuang. 2017. Pattern and coupling relationship between grain yield and agricultural labor changes at county level in China. Acta Geographica Sinica 72(6): 1063-1077.

Deng, X., J. Huang, S. Rozelle, J. Zhang and Z. Li. 2015. Impact of urbanization on arable land changes in China. Land Use Policy 45(45): 1-7.

Diouf, J. 2009. FAO's director-general on how to feed the world in 2050. Population \& Development Review 35(4): 837-839.

Du, T., S. Kang, X. Zhang and J. Zhang. 2014. China's food security is threatened by the unsustainable use of water resources in North and Northwest China. Food and Energy Security 3(1): 7-18.

Fang, F. and S. Cheng. 2009. Rice production capacity in China. Chinese Journal of Rice Science 23(6): 559-566.

Feng, Q., W.J.J. Yeung, Z. Wang and Y. Zeng. 2018. Age of retirement and human capital in an aging China, 2015-2050. European Journal of Population 1: 1-34.

Food and Agriculture Organization of the United Nations (FAO), 2017. Cereal yield (kg per hectare). FAO, Rome, Italy. Available at: https://data.worldbank.org/indicator/AG.YLD.CREL.KG

Food and Agriculture Organization of the United Nations (FAO), 2019. World food situation. FAO, Rome, Italy. Available at: http://www.fao.org/worldfoodsituation/csdb/en/?fb_=

Fujimori, S., T. Hasegawa, T. Masui and K. Takahashi. 2014. Land use representation in a global CGE model for long-term simulation: Cet vs. Logit functions. Food Security 6(5): 685-699. 
Fukase, E. and W. Martin. 2016. Who will feed China in the $21^{\text {st }}$ century? Income growth and food demand and supply in China. Journal of Agricultural Economics 67(1): 3-23.

Gandhi, V.P. and Z. Zhou. 2014. Food demand and the food security challenge with rapid economic growth in the emerging economies of India and China. Food Research International 63: 108-124.

Gao, C.L. and H.K. Wei. 2013. Prediction study on the urbanization trends of China. Modern Economic Science 35(4): 85-90.

Ghose, B. 2014. Food security and food self-sufficiency in China: from past to 2050. Food and Energy Security 3(2): 86-95.

Godrich, S.L., J. Lo, C.R. Davies, J. Darby and A. Devine. 2017. Which food security determinants predict adequate vegetable consumption among rural western Australian children? International Journal of Environmental Research and Public Health 14(1): 40-41.

Gregory, V., 2013. China's food security: past success and future challenges. Eurasian Geography \& Economics 54(1): 42-56.

Gu, C.L., W.H. Guan and H.L. Liu. 2017. Chinese urbanization 2050: SD modeling and process simulation. Science China Earth Sciences 60(6): 1-16.

He, C., Z. Liu, M. Xu, Q. Ma and Y. Dou. 2017. Urban expansion brought stress to food security in China: evidence from decreased cropland net primary productivity. Science of the Total Environment 576: 660-670.

Huang, J. and G. Yang. 2017. Understanding recent challenges and new food policy in China. Global Food Security 12: 119-126.

Jiang, Y. 2015. China's water security: current status, emerging challenges and future prospects. Environmental Science \& Policy 54: 106-125.

Liang, Y., J. Zhou, Q. Yang and H. Huang. 2016. Development status, function and prospect analysis of the multiple cropping in southern China. Crop Research 30(5): 572-578.

Lipton, M. and Y. Saghai. 2017. Food security, farmland access ethics, and land reform. Global Food Security 12: $59-66$.

Liu, P. 2016. The analysis on the trend and influencing factors of dietary patterns of inhabitants in China. PhD-thesis, Shanxi University of Finance and Economics, Shanxi, China.

Liu, Q., X. Liu and S. Wang. 2018a. Estimating China's food grains demand from 2020 to 2050 based on reasonable dietary pattern. Systems Engineering - Theory \& Practice 38(3): 615-622.

Liu, X., H. Shi and S.O. Statistics, 2017. Analysis of population structure in China under the universal twochild policy. Statistics \& Decision 8: 77-80.

Liu, Y., C. Wang, Z. Tang and Z. Nan. 2018b. Will farmland transfer reduce grain acreage? Evidence from Gansu province, China. China Agricultural Economic Review 10(2): 277-292.

Ma, Y.P., L.L. Sun, E. Yh and W. Wu. 2015. Predicting the impact of climate change in the next 40 years on the yield of maize in China. The Journal of Applied Ecology 26(1): 224.

Min, S., H. Waibel and J. Huang. 2017. Smallholder participation in the land rental market in a mountainous region of Southern China: impact of population aging, land tenure security and ethnicity. Land Use Policy 68: 625-637.

Nath, R., Y. Luan, W. Yang, C. Yang, W. Chen and Q. Li. 2015. Changes in arable land demand for food in India and China: a potential threat to food security. Sustainability 7: 5371-5397.

Peng, G.J., M.H. Chang, M. Fang, C.D. Liao, C.F. Tsai and S.H. Tseng. 2017. Incidents of major food adulteration in Taiwan between 2011 and 2015. Food Control 72: 145-152.

Perez-Escamilla, R., M.B. Gubert, B. Rogers and A. Hromi-Fiedler. 2017. Food security measurement and governance: assessment of the usefulness of diverse food insecurity indicators for policy makers. Global Food Security 14: 96-104.

Qiao, J., D. Yu and Y. Liu. 2017. Quantifying the impacts of climatic trend and fluctuation on crop yields in northern China. Environmental Monitoring \& Assessment 189(11): 532.

Rada, N., C. Wang and L. Qin. 2015. Subsidy or market reform? Rethinking China's farm consolidation strategy. Food Policy 57: 93-103. 
Shen, R., C. Wang and B. Sun. 2018. Soil related scientific and technological problems in implementing strategy of 'storing grain in land and technology'. Bulletin of Chinese Academy of Sciences 33(2): $135-144$.

Song, W., Z. Han and X. Deng. 2016. Changes in productivity, efficiency and technology of China's crop production under rural restructuring. Journal of Rural Studies 47: 563-576.

Tao, F., Z. Zhang and M. Yokozawa. 2011. Dangerous levels of climate change for agricultural production in China. Regional Environmental Change 11(1): 41-48.

Tao, F., Z. Zhang, S. Zhang and R.P. Rötter. 2016. Variability in crop yields associated with climate anomalies in China over the past three decades. Regional Environmental Change 16(6): 1715-1723.

Tao, J. and F. Zhou. 2014. Changing grain production in China: perspective on changing grain acreage. $3^{\text {rd }}$ International Conference of Agro-geoinformatics. August 11-14, 2014. Beijing, China, pp. 1-5.

United Nations (UN), 2017. World population projected to reach 9.8 billion in 2050, and 11.2 billion in 2100. United Nations, New York, NY, USA. Available at: https://www.un.org/development/desa/en/news/ population/world-population-prospects-2017.html

Valin, H., R.D. Sands, D.V.D. Mensbrugghe, G.C. Nelson, H. Ahammad and E. Blanc. 2014. The future of food demand: understanding differences in global economic models. Agricultural Economics 45(1): 51-67.

Wang, C., Z. Zhang and X. Fei. 2018. Efficiency and risk in sustaining China's food production and security: evidence from micro-level panel data analysis of Japonica rice production. Sustainability 10(4): 1282-1295.

Wu, J., J. Zhang, S. Wang and F. Kong. 2016. Assessment of food security in China: a new perspective based on production-consumption coordination. Sustainability 8(3): 183.

Wu, W., P.H. Verburg and H. Tang. 2014. Climate change and the food production system: impacts and adaptation in China. Regional Environmental Change 14(1): 1-5.

Xiao, D., J. Cao, H. Bai, Y. Qi and Y. Shen. 2017a. Assessing the impacts of climate variables and sowing date on spring wheat yield in the northern China. International Journal of Agriculture \& Biology 19: 1551-1558.

Xiao, Y., S. Cheng and G. Xie. 2017b. The balance between supply and consumption of the main types of grain in China. Journal of Natural Resources 32(6): 927-936.

Xie, C. and M.A. Marchant. 2015. Supplying China's growing appetite for poultry. International Food and Agribusiness Management Review 18(A): 317-334.

Xin, L., J. Wang and L. Wang. 2015. Prospect of per capita grain demand driven by dietary structure change in China. Resources Science 37(7): 1347-1356.

Yan, H. 2018. The influence of the two-child policy on China's population projection. International Journal of Statistics and Probability 7(3): 94.

Ye, L., Z. Li., P. Yang, W. Wu, G. Yang and Y. Fu. 2013. Climate change impact on China food security in 2050. Agronomy for Sustainable Development 33(2): 363-374.

Yi, F., D. Sun and Y. Zhou. 2015. Grain subsidy, liquidity constraints and food security - impact of the grain subsidy program on the grain-sown areas in China. Food Policy 50: 114-124.

Zhang, Z., G.P. Lei, H. Zhang and K.K. Shan. 2014. Time sequence analysis of high-standard basic farmland construction in 853 farm of Heilongjiang province. Economic Geography 8(3): 98-112.

Zhao, Z., X. Liu, P. Wang, J. Shuai, C. Yi and S. Xiao. 2014. The heat deficit indicator depicts the responses of rice yield to climate change in the northeastern three provinces of China. Regional Environmental Change 14(1): 27-38. 
